\title{
Mesenchymal stem cells improve mouse non-heart-beating liver graft survival by inhibiting Kupffer cell apoptosis via TLR4- ERK1/2-Fas/FasL-caspase3 pathway regulation
}

Yang Tian ${ }^{1 \dagger}$, Jingcheng Wang ${ }^{1+}$, Wei Wang ${ }^{1}$, Yuan Ding ${ }^{2}$, Zhongquan Sun ${ }^{2}$, Qiyi Zhang ${ }^{2}$, Yan Wang ${ }^{1}$, Haiyang Xie ${ }^{2,3}$, Sheng Yan ${ }^{1,2,3^{*}}$ and Shusen Zheng ${ }^{1,2,3^{*}}$

\begin{abstract}
Background: Liver transplantation is the optimal treatment option for end-stage liver disease, but organ shortages dramatically restrict its application. Donation after cardiac death (DCD) is an alternative approach that may expand the donor pool, but it faces challenges such as graft dysfunction, early graft loss, and cholangiopathy. Moreover, DCD liver grafts are no longer eligible for transplantation after their warm ischaemic time exceeds 30 min. Mesenchymal stem cells (MSCs) have been proposed as a promising therapy for treatment of certain liver diseases, but the role of MSCs in DCD liver graft function remains elusive.

Methods: In this study, we established an arterialized mouse non-heart-beating (NHB) liver transplantation model, and compared survival rates, cytokine and chemokine expression, histology, and the results of in vitro co-culture experiments in animals with or without MSC infusion.

Results: MSCs markedly ameliorated NHB liver graft injury and improved survival post-transplantation. Additionally, MSCs suppressed Kupffer cell apoptosis, Th1/Th17 immune responses, chemokine expression, and inflammatory cell infiltration. In vitro, PGE2 secreted by MSCs inhibited Kupffer cell apoptosis via TLR4-ERK1/2-caspase3 pathway regulation.

Conclusion: Our study uncovers a protective role for MSCs and elucidates the underlying immunomodulatory mechanism in an NHB liver transplantation model. Our results suggest that MSCs are uniquely positioned for use in future clinical studies owing to their ability to protect DCD liver grafts, particularly in patients for whom DCD organs are not an option according to current criteria.
\end{abstract}

Keywords: Mesenchymal stem cells, Donation after cardiac death, Graft survival, Kupffer cells, Apoptosis,

\section{Background}

Liver transplantation was first introduced by Dr. Starzl over five decades ago, and is still considered to be the optimal treatment for end-stage liver disease [1]. This procedure is currently accepted and performed by many

\footnotetext{
*Correspondence: shengyan@zju.edu.cn; shusenzheng@zju.edu.cn ${ }^{\dagger}$ Equal contributors

${ }^{1}$ Division of Hepatobiliary and Pancreatic Surgery, Department of Surgery, the First Affiliated Hospital, School of Medicine, Zhejiang University, Hangzhou, China

Full list of author information is available at the end of the article
}

transplant centres worldwide, but organ shortages remain a prevalent problem [2] which is reflected in the median time to transplant among waiting-listed candidates. For example, in the United States, the median time increased from 14.8 months in 2004 to 19.5 months in 2011 [3]. As a result, death rates among patients on the waiting list have increased over the past two decades [2]. Therefore, donation after cardiac death (DCD), which would expand the pool of available donors, has been proposed as an alternative to ameliorate the organ shortage crisis. In the United States, the percentage of 
DCD organs has grown annually from 1\% in 1996 to $10 \%$ in 2007 [4]. However, liver graft ischaemia/reperfusion injury (IRI) during DCD donation is inevitable, and the incidence of primary graft dysfunction, early graft loss, and cholangiopathy is fairly high [5-9]. Evidence-based medicine has demonstrated the relatively good quality and safety of DCD grafts with a warm ischaemic time of less than $30 \mathrm{~min}$, and this criterion is implemented in transplantation centres worldwide. For grafts with warm ischaemic time less than $30 \mathrm{~min}$, the primary negative outcome of $\mathrm{DCD}$ liver transplantation is late ischaemic cholangiopathy rather than primary non-function, whereas for grafts with warm ischaemic time over $30 \mathrm{~min}$, the primary negative outcome of DCD liver transplantation is early mortality. Numerous studies have been carried out in recent years to identify novel strategies to alleviate DCD liver graft injury.

Mesenchymal stem cells (MSCs) are multipotent cells that are capable of differentiating into specific osteoblastic, adipogenic, and chondrogenic lineages [10]. With the development of regenerative and translational medicine, MSCs have become a subject of research interest because of their low immunogenicity and immunomodulatory properties [11]. MSCs exert powerful immunosuppressive functions via paracrine effects and cell-cell contactdependent interactions, and MSCs also inhibit the proliferation of activated lymphocytes, thereby providing survival signals to resting immune cells and subsequently stimulating the induction of regulatory immune cells [12]. Among various soluble mediators, inducible nitric oxide synthase (iNOS), transforming growth factor (TGF) $\beta$, indoleamine 2,3-dioxygenase (IDO), and prostaglandin E2 (PGE2) are the primary factors responsible for the therapeutic potential of MSCs [13]. Recently, MSCs have been applied to treat autoimmune diseases, diabetes, liver diseases such as fibrosis, non-alcoholic fatty liver cirrhosis, fulminant hepatic failure, and solid organ transplantation [14-18]. However, it is unclear whether MSCs effectively protect DCD liver grafts, and the mechanisms underlying this hypothetical protection remain unknown.

The mouse orthotopic liver transplantation model has unique advantages over rat or swine models, owing to the well-characterized mouse genome and the widespread availability of genetic modification techniques, thus making it a powerful research tool to investigate liver biology, transplant immunology, and DCD-related IRI [19]. However, no optimal mouse non-heart-beating (NHB) liver transplantation model for DCD research has been reported. In this study, we established a standard arterialized mouse NHB liver transplantation model and explored the optimal conditions for NHB modelling. Using this model, we provide the first demonstration of the ability of MSCs to effectively ameliorate NHBinduced graft injury and significantly improve recipient survival by inhibiting Kupffer cell apoptosis. In addition, this study highlights the importance of Kupffer cells in the protective effects exerted by MSCs on NHB liver grafts. Furthermore, MSC-mediated protection against Kupffer cell apoptosis is primarily facilitated by secreted PGE2 via TLR4-ERK1/2-Fas/FasL-caspase3 signalling pathway regulation.

\section{Methods}

Mice

Male C57Bl/6 $\left(\mathrm{H}_{2}^{\mathrm{b}}\right)$ and CBF1 $\left(\mathrm{H}_{2}^{\text {bd }}\right)$ mice aged $8-12$ weeks were purchased from the Model Animal Research Center of Nanjing University. All mice were maintained in autocephalous individually ventilated cages (IVC) in a specific-pathogen-free environment and given standard laboratory chow and tap water ad libitum. Animal feeding practices and all experiments involving animals were conducted in accordance with the Guidelines for the Care and Use of Laboratory Animals and received the approval of the Animal Ethics Committees of Zhejiang University (Hangzhou, China).

\section{Establishment of an arterialized mouse NHB liver transplantation model}

$\mathrm{C} 57 \mathrm{Bl} / 6$ mice were used as donors, and CBF1 mice were used as recipients. Mouse NHB orthotropic liver transplantation was performed by two licensed animal surgeons using the "double cuff" method, as described in previous studies $[20,21]$, and the hepatic artery was reconstructed via an aortic trunk method [22]. Briefly, each donor was injected with 100 IU heparin via the tail vein under inhalation anaesthesia. Then, a cross incision was made to expose the donor liver, and the ligaments around the liver were dissected. $\mathrm{CO}_{2}$ asphyxiation was administered. NHB timing began when cardiac arrest was confirmed by palpation. After NHB time at $0 \mathrm{~min}$, $5 \mathrm{~min}, 10 \mathrm{~min}$ and $20 \mathrm{~min}$, liver grafts were perfused with cold University of Wisconsin perfusate, harvested with the hepatic-celiac axis-aortic artery segment, and preserved in UW solution at $4{ }^{\circ} \mathrm{C}$. The suprahepatic inferior vena cava was connected using a continuous suture approach, and the portal vein and the infrahepatic inferior vena cava were reconstructed via the "double cuff" method. The common bile duct was connected with a biliary stent. Subsequently, portal vein commencement was carried out at a cold ischaemic time of $120 \mathrm{~min}$. To perform artery reconstruction, the hepaticceliac axis-aortic artery segment was anastomosed to the recipient aorta by using an "end-to-side anastomosis" technique involving interrupted sutures. Because surgical fault may lead to uncontrolled arterial bleeding or thrombus and result in recipient death, only recipients with perfect hepatic arteriopalmus and without unexpected bleeding were included into our experiments to avoid any surgical influence on recipient survival. After 
transplantation, all recipients received subcutaneous injections of saline and antibiotics and were maintained in a temperature-controlled IVC unit with a $12 \mathrm{~h}$ light-dark cycle and given free access to standard laboratory chow and tap water. Recipient survival was observed and recorded every $6 \mathrm{~h}$.

\section{Isolation, culture, and retroviral transduction of immortalized T40-MSCs}

Immortalized T40-MSCs originally isolated from the bone marrow of $\mathrm{C} 57 \mathrm{Bl} / 6$ mice were a kind gift from Prof. Weimin Fan of Zhejiang University. In brief, a male 8-week-old $\mathrm{C} 57 \mathrm{Bl} / 6$ mouse was sacrificed, and whole bone marrow was retrieved by flushing the bones with Dulbecco's modified Eagle's medium (DMEM; GIBCO, Waltham, MA, USA). All bone marrow cells were cultured in DMEM with 10\% foetal bovine serum (FBS; GIBCO) for $48 \mathrm{~h}$. Non-adherent haematopoietic cells were discarded. Adherent cells were then washed three times with phosphate-buffered saline (PBS) and replenished with $15 \mathrm{~mL}$ fresh DMEM containing 10\% FBS. When the cells grew to $60 \%$ confluence, they were transfected with a T40-expressing retroviral vector.

To achieve T40-expressing retrovirus packaging, HEK293 cells were plated at a cell density of approximately $50 \%$. After $3-5 \mathrm{~h}$, the cells were transfected with $250 \mu \mathrm{L}$ Opti-MEM plus $37.5 \mu \mathrm{L}$ of a solution containing $15 \mu \mathrm{L}$ Lipofect AMINE (Invitrogen, Waltham, MA, USA), $7.5 \mu \mathrm{L}$ of the packaging plasmid pAmpho and $15 \mu \mathrm{L}$ pSSRV60-T40. The medium was discarded $3-5 \mathrm{~h}$ later and replaced with $4 \mathrm{~mL}$ fresh complete DMEM. Retrovirus-containing supernatants were collected at 36 , 60 , and $84 \mathrm{~h}$. The generated virus was kept at $4{ }^{\circ} \mathrm{C}$ or directly used to infect MSCs. Immortalized T40-MSCs were generated by transducing MSCs twice per day for 2 consecutive days. Hygromycin B $(0.2 \mathrm{mg} / \mathrm{mL}$; SigmaAldrich, St. Louis, MO, USA) selection began at the end of the second round of infection.

\section{Differentiation and identification of MSCs}

Adipogenic and osteogenic differentiation were induced in vitro, and MSC identification was carried out. To achieve adipogenic differentiation, MSCs were cultured with $1 \mu \mathrm{M}$ dexamethasone and $0.2 \mathrm{mM}$ indomethacin in DMEM plus $10 \%$ FBS, and the conditional medium was changed every other day. After 7 days, adipocytic differentiation was examined through oil red $\mathrm{O}$ staining. Osteogenic MSC differentiation was performed with conditional medium containing $100 \mathrm{mM}$ dexamethasone, $10 \mathrm{mM} \beta$-glycerophosphate disodium, and $50 \mu \mathrm{M}$ L-ascorbic acid-2-phosphate. The medium was changed every other day, and 2 weeks later MSCs were stained with alizarin red to examine calcium deposition. All conditional medium supplements were purchased from Sigma-Aldrich.

\section{MSC infusion and $\mathrm{GdCl}_{3}$ administration}

MSCs in the logarithmic phase were trypsinised and suspended in DMEM at a concentration of $5 \times 10^{7} / \mathrm{mL}$. After portal vein commencement, a $20-\mu \mathrm{L}$ suspension containing $10^{6}$ MSCs was injected intrasplenically. Electrocoagulation was applied at the puncture point to stop bleeding. In other experiments, $20 \mathrm{mg} / \mathrm{Kg}$ gadolinium chloride $\left(\mathrm{GdCl}_{3}\right.$; Sigma-Aldrich) solution was administered intraperitoneally to donor $\mathrm{C} 57 \mathrm{Bl} / 6$ mice $24 \mathrm{~h}$ before transplantation to eliminate intrahepatic Kupffer cells.

\section{Liver function test and histological evaluation}

Under inhalation anaesthesia, blood was collected from the inferior vena cava, and serum alanine aminotransferase (ALT) and aspartate aminotransferase (AST) were measured using an automatic biochemical analyser in the clinical laboratory of our hospital. Liver grafts were harvested, formalin-fixed, sectioned, and stained with haematoxylin and eosin for histopathological evaluation using the Suzuki Score System (Table 1). Each graft section was examined in a blinded fashion by an experienced pathologist.

\section{Quantitative real-time polymerase chain reaction}

The mRNA levels of cytokines and chemokines were detected by quantitative real-time polymerase chain reaction (RT-PCR), as described in our previous study [20, 23]. Briefly, total RNA was extracted from frozen grafts by using TRIzol reagent (Invitrogen) and then reverse-transcribed into cDNA using a reverse transcriptase kit (Bio-Rad, Hercules, CA, USA). cDNA primers and iTaq Universal SYBR Green Supermix (Bio-Rad) were added to PCR plates, and PCR was carried out with an Applied Biosystems 7900 PCR System. Relative mRNA quantification was performed using the $2^{-\triangle \Delta \mathrm{Ct}}$ method according to the manufacturer's manual. Gene-specific primers are shown in Table 2.

\section{Immunofluorescence and terminal deoxynucleotidyl} transferase dUTP nick end labelling (TUNEL) detection For immunofluorescence analysis, frozen sections of liver graft specimens were incubated with anti-mouse

Table 1 Standards of Suzuki score for liver injury

\begin{tabular}{llll}
\hline Score & Congestion & Vacuole degeneration & Necrosis \\
\hline 0 & None & None & None \\
1 & Slight & Slight & Single cell \\
2 & Mild & Mild & $<30 \%$ \\
3 & Moderate & Moderate & $31-60 \%$ \\
4 & Severe & Severe & $>60 \%$ \\
\hline
\end{tabular}


Table 2 Sequences of primers used in quantitative RT-PCR

\begin{tabular}{|c|c|c|c|}
\hline \multirow{2}{*}{$\frac{\text { Gene }}{\beta \text {-actin }}$} & \multicolumn{2}{|c|}{ Sequences } & \multirow{2}{*}{$\frac{\text { Length (base) }}{23}$} \\
\hline & Forward: & CATTGCTGACAGGATGCAGAAGG & \\
\hline & Reverse: & TGCTGGAAGGTGGACAGTGAGG & 22 \\
\hline \multirow[t]{2}{*}{ IL1a } & Forward: & ACGGCTGAGTTTCAGTGAGACC & 22 \\
\hline & Reverse: & CACTCTGGTAGGTGTAAGGTGC & 22 \\
\hline \multirow[t]{2}{*}{ IL1 $\beta$} & Forward: & TGGACCTTCCAGGATGAGGACA & 22 \\
\hline & Reverse: & GTTCATCTCGGAGCCTGTAGTG & 22 \\
\hline \multirow[t]{2}{*}{ IL2 } & Forward: & GCGGCATGTTCTGGATTTGACTC & 23 \\
\hline & Reverse: & CCACCACAGTTGCTGACTCATC & 22 \\
\hline \multirow[t]{2}{*}{ IL4 } & Forward: & ATCATCGGCATITTGAACGAGGTC & 24 \\
\hline & Reverse: & ACCTTGGAAGCCCTACAGACGA & 22 \\
\hline \multirow[t]{2}{*}{ IL6 } & Forward: & TACCACTTCACAAGTCGGAGGC & 22 \\
\hline & Reverse: & CTGCAAGTGCATCATCGTTGTTC & 23 \\
\hline \multirow[t]{2}{*}{ IL10 } & Forward: & CGGGAAGACAATAACTGCACCC & 22 \\
\hline & Reverse: & CGGTTAGCAGTATGTTGTCCAGC & 23 \\
\hline \multirow[t]{2}{*}{ TNFa } & Forward: & GGTGCCTATGTCTCAGCCTCTT & 22 \\
\hline & Reverse: & GCCATAGAACTGATGAGAGGGAG & 23 \\
\hline \multirow[t]{2}{*}{ IFNy } & Forward: & CAGCAACAGCAAGGCGAAAAAGG & 23 \\
\hline & Reverse: & CAGCAACAGCAAGGCGAAAAAGG & 23 \\
\hline \multirow[t]{2}{*}{$\mathrm{F} 4 / 80$} & Forward: & CGTGTTGTTGGTGGCACTGTGA & 22 \\
\hline & Reverse: & CCACATCAGTGTTCCAGGAGAC & 22 \\
\hline
\end{tabular}

IFN interferon, IL interleukin, $R T-P C R$ real-time polymerase chain reaction, TNF tumour necrosis factor

F4/80-FITC (Abcam, Cambridge, MA, USA) at $4{ }^{\circ} \mathrm{C}$ overnight.

Proliferating Kupffer cells in frozen graft sections were stained with anti-mouse F4/80-Alexa Flour 647 (Abcam) and anti-Ki67 antibodies (Abcam) at $4{ }^{\circ} \mathrm{C}$ overnight. Sections were then incubated with a goat-anti-rat IgG-Alexa Flour 488 secondary antibody (Abcam) for $2 \mathrm{~h}$ at room temperature.

Apoptotic Kupffer cells in frozen graft sections were stained with anti-mouse F4/80-Alexa Flour 647 (Abcam) and detected in a TUNEL assay with an ApopTag ${ }^{\circledR}$ Plus Peroxidase in Situ Apoptosis Kit (EMD Millipore, Darmstadt, Germany). Detection and all measurements were carried out following the manufacturer's instructions.

All of the sections were then mounted in Mounting Medium with DAPI (Vector Laboratories, Burlingame, CA, USA) and scanned with a two-photon laser confocal microscope (Olympus, Tokyo, Japan).

\section{Immunohistochemistry staining}

For immunohistochemistry staining, antigen retrieval and goat serum blocking were first performed, and then paraffin-embedded graft sections were incubated with anti-myeloperoxidase (MPO; Abcam) and anti-CD3 (R\&D, Minneapolis, MN, USA) at $4{ }^{\circ} \mathrm{C}$ overnight. Sections were then incubated with a goat-anti-rabbit or goat-anti-rat IgG secondary antibody conjugated to horseradish peroxidase for $2 \mathrm{~h}$ at room temperature (Invitrogen). 3,3'-diaminobenzidine peroxidase substrate was used as a detection reagent (Vector Laboratories). All sections were visualized using BX41 microscopy (Olympus).

\section{Immunoassay and MPO measurement}

Serum cytokine and chemokine protein levels were measured with a Luminex-200 system using the ProcartaPlex Mouse Cytokine \& Chemokine Panel Kit (eBioscience, San Diego, CA, USA), and serum MPO activity was measured using an MPO Activity Colorimetric Assay Kit (Biovision, Milpitas, CA, USA). Detection and all measurements were carried out following the manufacturer's instructions.

\section{MSC-macrophage in vitro co-culture}

In vitro experiments were carried out using the mousederived RAW264.7 cell line, which was purchased from the Chinese Academy of Sciences, to represent Kupffer cells. Generally, $5 \times 10^{5}$ macrophages per well were seeded in a six-well plate, and $10^{5}$ MSCs were seeded in a $0.4-\mu \mathrm{m}$ polycarbonate membrane insert Transwell (Corning, Corning, NY, USA) in medium containing or lacking NS-398 (5 $\mu \mathrm{M}$; Sigma-Aldrich). After $24 \mathrm{~h}$, the medium was changed once to remove non-adherent dead cells. After $2 \mathrm{~h}$ of incubation at $37^{\circ} \mathrm{C}$ without $\mathrm{O}_{2}$, the macrophages were transferred into co-culture with the Transwells containing MSCs, and 0, 100, 200, 400, or $800 \mu \mathrm{M}$ hydrogen peroxide $\left(\mathrm{H}_{2} \mathrm{O}_{2}\right)$ was added to specific wells. Then, the co-cultured cells were incubated at $37{ }^{\circ} \mathrm{C}$ with $5 \% \mathrm{CO}_{2}$ for $6 \mathrm{~h}$ to mimic the process of IRI during NHB liver transplantation in vivo.

\section{Flow cytometry to detect co-cultured macrophage apoptosis}

After $6 \mathrm{~h}$ of co-culture, all macrophages were collected for early apoptosis detection by flow cytometry using an Annexin V-FITC/PI apoptosis detection kit (DOJINDO, Kumamoto, Japan) according to the manufacturer's manual.

\section{Western blotting}

The expression of specific target proteins was examined by Western blotting, as described in our previous study [23]. Total protein fractions from co-cultured macrophages were extracted with RIPA and protease and phosphatase inhibitor cocktail (Thermo Fisher, Waltham, MA, USA). Anti-TLR2 (Epitomics, Cambridge, MA, USA), anti-TLR4 (Abcam), anti-ERK1/2 (Cell Signaling Technology, Danvers, MA, USA), anti-pERK1/2 (Cell Signaling Technology), anti-Fas (Biovision, Milpitas, CA, USA), anti-FasL (Biovision), anti-cleaved caspase3 (Cell Signaling Technology), and anti- $\beta$-actin (Abcam) antibodies were incubated with 
macrophage protein-containing nitrocellulose membranes overnight. A ChemiDoc Imaging System was used to develop the images (Bio-Rad, Hercules, CA, USA). Grey values were calculated and analysed for each band with ImageLab software (Bio-Rad).

\section{Statistics}

Recipient survival was expressed graphically using the Kaplan-Meier method. All other data are presented as the mean \pm SEM and were analysed using GraphPad Prism 5.0.1 software (GraphPad Prism Software Inc., La Jolla, CA, USA). A log-rank (Mantel-Cox) test was used for survival rate analysis, and Student's $t$ test was applied to assess data obtained from different groups. Two-sided $P<0.05$ was considered to be statistically significant.

\section{Results}

\section{NHB time extension reduces the survival rate with} aggravated liver graft injury

To establish an optimal mouse model for NHB liver graft research, arterialized orthotopic liver transplantations were performed, and different NHB timing options were tested. Sham operations were carried out as normal controls. For the $\mathrm{NHB}_{0 \mathrm{~min}}$ group, all recipients survived more than 14 days post-transplantation. Only $75 \%$ of recipients survived at 14 days in the $\mathrm{NHB}_{5 \min }$ group, and the 14-day survival rate was reduced to $37.5 \%$ and $12.5 \%$ in the $\mathrm{NHB}_{10 \text { min }}$ group and $\mathrm{NHB}_{20 \text { min }}$ group, respectively, thus revealing the increased incidence of primary graft dysfunction and early graft dysfunction with NHB time extension (Fig. 1a). Serum levels of ALT/AST, the most sensitive IRI indicator in liver grafts, rise rapidly once reperfusion begins and reach a peak at $6 \mathrm{~h}$ posttransplantation. Afterwards, the liver graft initiates certain mechanisms to repair IRI and hepatocellular damage, and serum ALT/AST levels decrease gradually. However, if IRI is too severe for the graft to repair itself, liver dysfunction occurs within several days, ultimately resulting in recipient death [24-26]. To evaluate liver graft injury, serum and liver specimens were collected and examined at $6 \mathrm{~h}$ post-transplantation when inflammation peaked. A gradual increase in serum ALT and AST levels was detected in these groups (Fig. 1b and c). Histopathological examination indicated 30\% hepatocellular oedema with mild inflammatory cell infiltration in the $\mathrm{NHB}_{0 \text { min }}$ group, $60 \%$ hepatocellular oedema with widened hepatic sinusoids in the $\mathrm{NHB}_{5 \text { min }}$ group, severe hepatocellular oedema with spotty necrosis in the

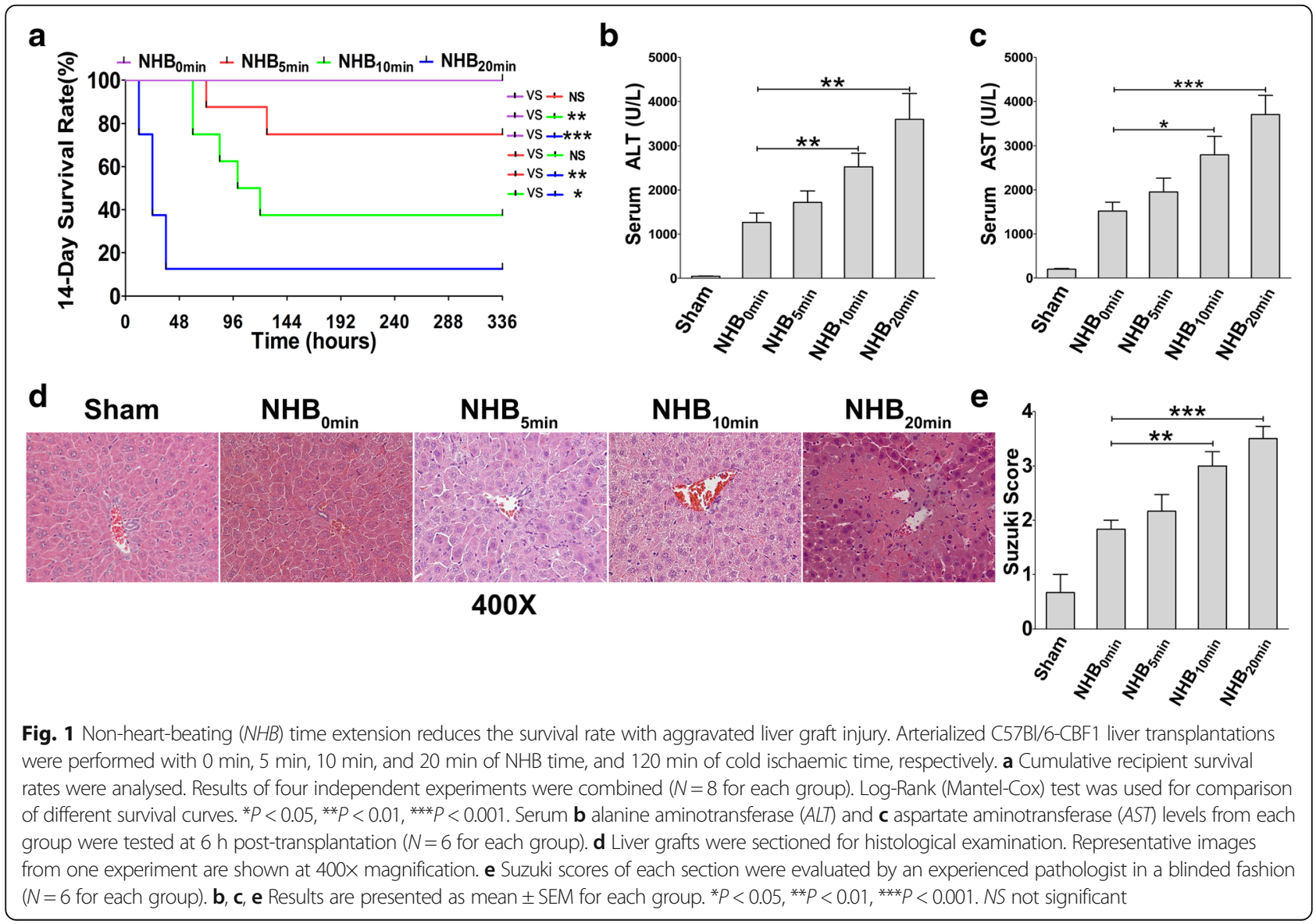


$\mathrm{NHB}_{10 \text { min }}$ group, and patchy necrosis accompanied by severe inflammatory cell infiltration and widened sinusoids in the $\mathrm{NHB}_{20 \text { min }}$ group (Fig. 1d). These results were consistent with a clear increase in the Suzuki scores of the liver grafts (Fig. 1e). Together, these data suggested that NHB time extension aggravated liver graft injury, resulting in a dramatic reduction in the survival rate after liver transplantation.

\section{Impaired Th1/Th2 responses and Kupffer cells after NHB liver transplantation}

Th1 (tumour necrosis factor (TNF) $\alpha$, interferon (IFN) $\gamma$, and interleukin (IL)2) and Th17 (IL17) cytokines are proinflammatory during pathogenesis, whereas Th2 cytokines (IL4, IL6, and IL10) exert immunomodulatory functions that inhibit severe inflammation in the body. Given the critical role of Th1/Th2 immune responses in liver selfhomeostasis during pathological events [27], the intrahepatic mRNA expression of classical Th1/Th2 cytokines was determined by performing quantitative RT-PCR. Unexpectedly, Th1 and Th2 cytokine mRNA levels did not increase with aggravated liver graft injury when NHB time was extended. In contrast, with the exception of IL2 and IL4, the mRNA expression of all other Th1 and Th2 cytokines, including TNF $\alpha$, IFN $\gamma$, IL6, and IL10, was downregulated, thus indicating the impairment of intrahepatic Th1/Th2 cell responses after NHB liver transplantation (Fig. 2a and b). Kupffer cells are very sensitive to pathological factors during IRI, and initiate Th1/Th2 responses by secreting certain cytokines and chemokines. To investigate Kupffer cell status in the context of Th1/Th2 response impairment, we first detected the intrahepatic mRNA expression of F4/80, a classic surface marker of Kupffer cells [28]. As expected, F4/80 mRNA levels decreased robustly as NHB time was extended (Fig. 2c). Similarly, immunofluorescence staining of frozen grafts showed a dramatic loss of F4/80-positive Kupffer cells within different groups (Fig. 2d and e). Thus, as NHB time was extended, aggravated liver IRI led to a dramatic loss of Kupffer cells and impaired Th1/Th2 immune responses post-transplantation.

In addition, we compared survival rates, ALT and AST levels, and graft histopathological injury in different NHB groups and determined the optimal conditions for the mouse arterialized NHB liver transplantation model to be an NHB time of $10 \mathrm{~min}$ and a cold ischaemic time of $120 \mathrm{~min}$; under these conditions, any effects of various interventions were conveniently observed as changes in recipient survival.

\section{MSCs ameliorate NHB-induced graft injury and increase the recipient survival rate}

We evaluated the adipogenic and osteogenic differentiation potential of MSCs in conditioned medium in vitro. Intra-MSC lipid droplets stained with oil red O [29] and calcium deposition stained with alizarin red $\mathrm{S}$ were clearly observed (Fig. 3a) [30].

To examine the role of MSCs in mouse NHB liver transplantation, MSCs were slowly intrasplenically infused after portal vein commencement; under these conditions, the majority of MSCs gradually migrate into the hepatic sinusoids through the portal vein and avoid portal vein embolization [31-33]. MSC infusion effectively improved the survival rate post-transplantation, with $100 \%$ survival of recipients by day 14 , compared with $37.5 \%$ survival in the $\mathrm{NHB}_{10 \text { min }}$ group (Fig. $3 \mathrm{~b}$ ), a result consistent with a significant decrease in serum ALT and AST levels at $6 \mathrm{~h}$ post-transplantation (Fig. 3c and d). Histopathological examination showed normal hepatocellular morphology without oedema, vacuolar degeneration, or necrosis, and a significant decrease in the Suzuki scores in the $\mathrm{MSC}_{10 \mathrm{~min}}$ group, which significantly differed from the severe hepatocellular oedema with spotty necrosis observed in the $\mathrm{NHB}_{10 \text { min }}$ group (Fig. $3 \mathrm{e}$ and $\mathrm{f}$ ). Thus, MSC infusion significantly ameliorated warm ischaemia-induced liver graft injury and promoted recipient survival after NHB liver transplantation.

\section{MSCs protect and restore Kupffer cells by inhibiting apoptosis but not by promoting proliferation}

As mentioned above, Kupffer cells were dramatically impaired by extended NHB injury, thus indicating a close relationship between graft quality and Kupffer cell status. Because MSCs effectively protect against NHB liver graft injury, we sought to determine how MSC infusion affects Kupffer cells. To investigate this question, F4/80 mRNA expression and immunofluorescence staining were evaluated. Interestingly, MSCs significantly improved F4/80 mRNA expression in liver grafts compared with the $\mathrm{NHB}_{10 \mathrm{~min}}$ group (Fig. $4 \mathrm{a}$ ). Moreover, an obvious increase in F4/80-positive cells was detected using confocal microscopy (Fig. $4 \mathrm{~b}$ and c), thus suggesting the restoration of Kupffer cells due to MSC infusion.

However, it is unclear how MSCs promote Kupffer cell restoration. Thus, in situ proliferating and apoptotic Kupffer cells were detected by performing Ki67-F4/80 and TUNEL-F4/80 immunofluorescent staining, respectively. Proliferating cells were mainly non-parenchymal cells in the $\mathrm{NHB}_{10 \text { min }}$ group, while proliferating cells could seldom be detected in the $\mathrm{MSC}_{10 \mathrm{~min}}$ group (Fig. 4d). However, the percentage of Ki67-positive Kupffer cells showed no difference between these two groups (Fig. 4e). Meanwhile, sporadic hepatocellular apoptosis and non-parenchymal cell apoptosis were detected in the $\mathrm{NHB}_{10 \text { min }}$ group, which was rarely observed in the $\mathrm{MSC}_{10 \mathrm{~min}}$ group (Fig. 4f). Besides, the percentage of TUNEL-positive Kupffer cells in the $\mathrm{NHB}_{10 \text { min }}$ group was significantly higher than in the $\mathrm{MSC}_{10 \text { min }}$ group (Fig. 4g). These results indicated that MSCs protected 


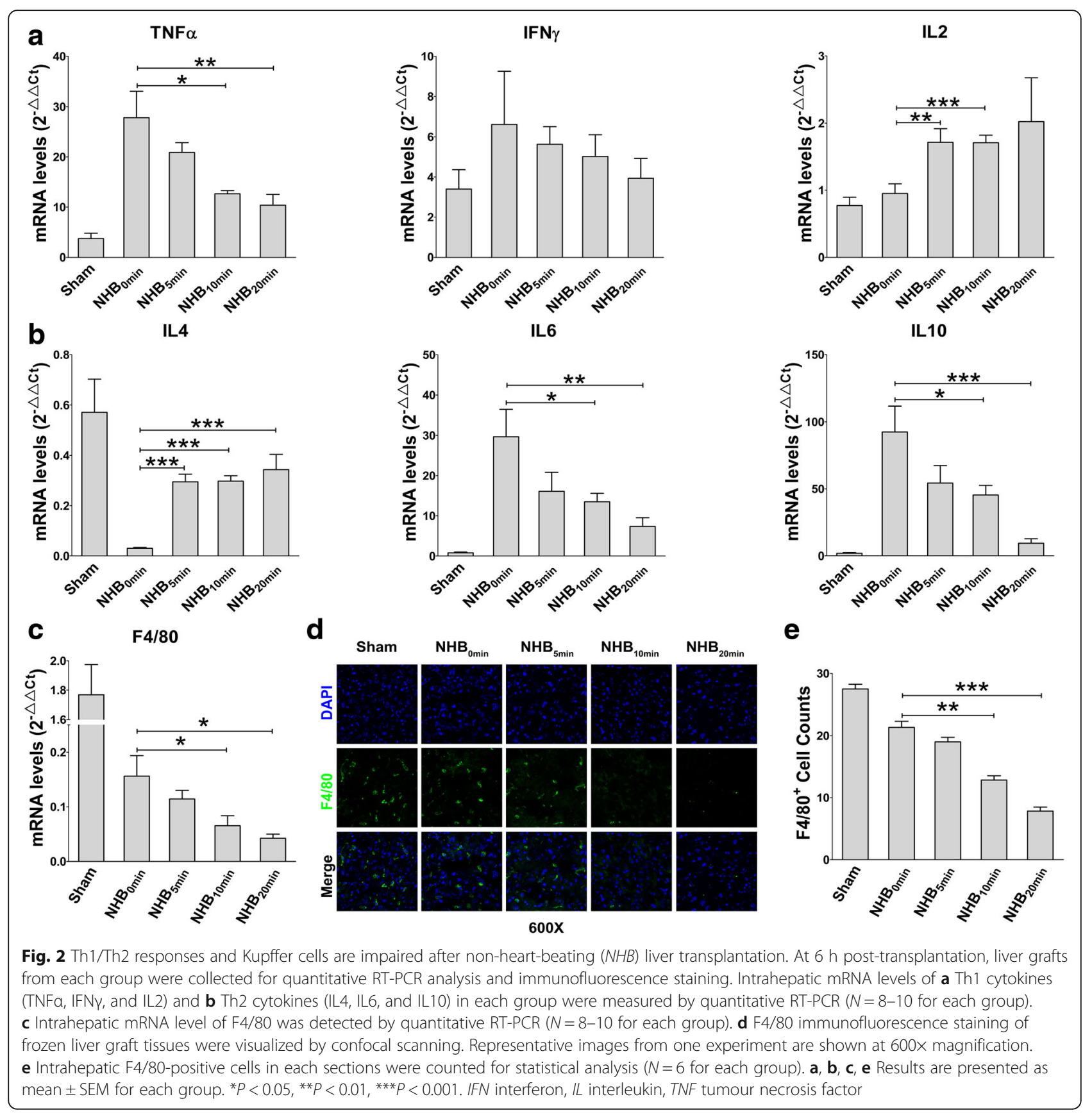

Kupffer cells by inhibiting their apoptosis but not by promoting their proliferation. We hypothesized that the initiation of certain proliferative mechanisms by nonparenchymal cells might replace specific cells lost due to apoptosis resulting from severe injury and graft damage in the $\mathrm{NHB}_{10 \text { min }}$ group. While MSC infusion reversed the damage caused by IRI, non-parenchymal cells and hepatocytes rarely showed Ki67 and TUNEL expression. However, the underlying mechanisms require further investigation.

\section{MSC-mediated protection of NHB grafts depends on Kupffer cells}

Although we observed a close relationship between MSCs and Kupffer cells, we lacked more direct evidence. Because MSCs recruit peripheral lymphocytes into the liver graft by secreting a series of chemokines, further study is needed to determine whether the restoration of $\mathrm{F} 4 / 80^{+}$cells after MSC infusion is related to peripheral macrophage recruitment. The administration of $20 \mathrm{mg} / \mathrm{Kg}$ doses of $\mathrm{GdCl}_{3}$ causes Kupffer cell apoptosis and selectively blocks Kupffer 


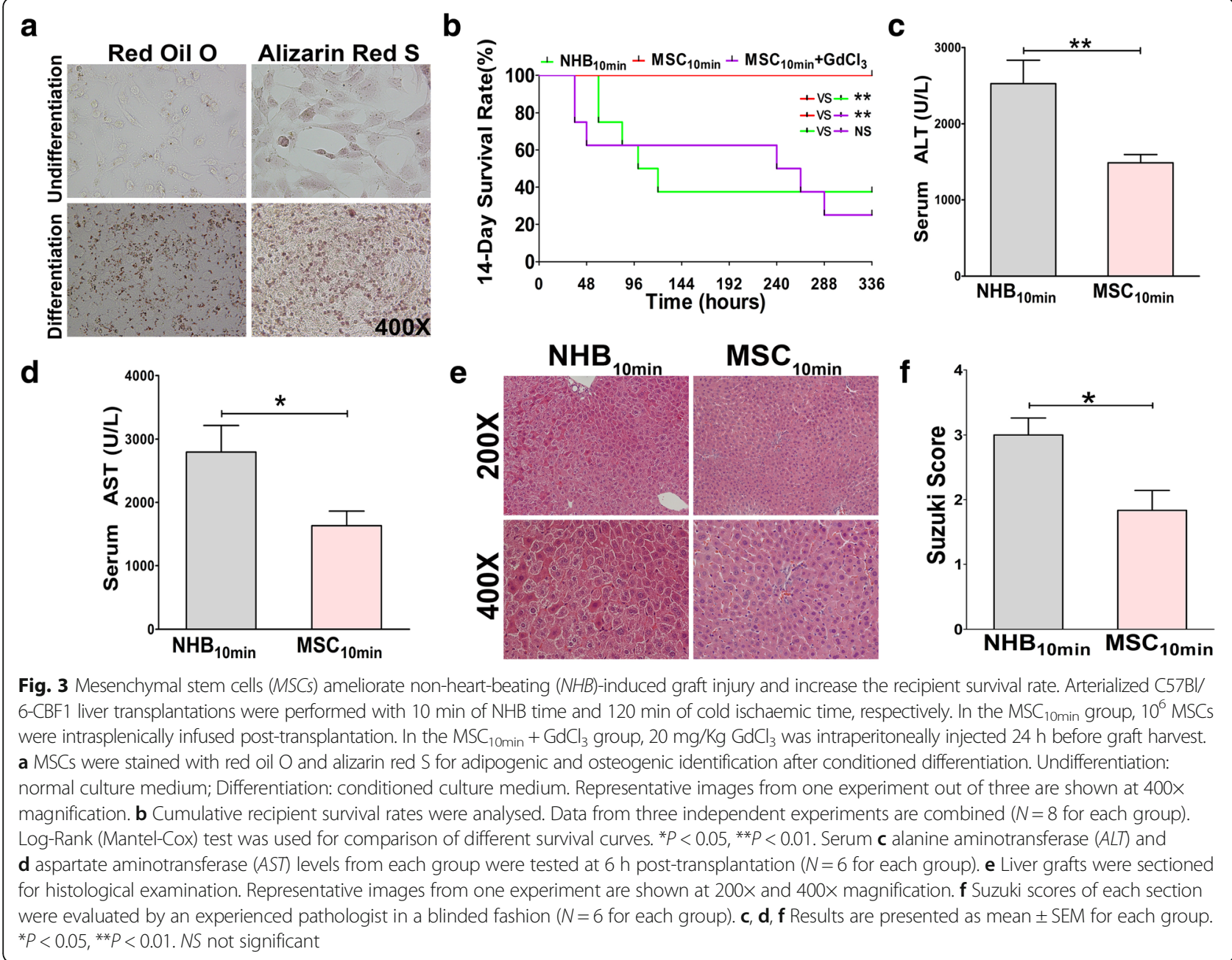

cell effector functions but does not cause liver parenchymal cell toxicity [31]. Rather than shortening the survival of injected mice, the administration of $20 \mathrm{mg} / \mathrm{Kg}$ doses of $\mathrm{GdCl}_{3}$ may protect the liver against IRI [34]. To elucidate the true role of Kupffer cells in the MSC-mediated protection of $\mathrm{NHB}$ grafts, $20 \mathrm{mg} / \mathrm{Kg} \mathrm{GdCl}$ was applied in $\mathrm{NHB}$ donors $24 \mathrm{~h}$ before surgical procedures, so as not to affect the recipient's bone marrow-derived macrophage recruitment into the liver graft post-transplantation. After the depletion of intrahepatic Kupffer cells with $\mathrm{GdCl}_{3}, \mathrm{NHB}$ liver grafts were transplanted into recipients with simultaneous MSC infusion. Unexpectedly, the 14-day survival rate dramatically decreased to $25 \%$ in the $\mathrm{GdCl}_{3}$-pretreated group (Fig. 3b), and this result was not significantly different from that observed for the $\mathrm{NHB}_{10 \text { min }}$ group. Thus, the protective effects of MSCs on NHB liver grafts appear to depend on Kupffer cells. Furthermore, the restoration of $\mathrm{F} 4 / 80^{+}$cells after MSC infusion is dependent on the direct protection of Kupffer cells against apoptosis, not the recruitment of peripheral macrophages into the liver grafts.
MSCs suppress Th1/Th17 cells but promote IL10 secretion As mentioned previously, classical cytokines were investigated to assess Th1/Th2/Th17 responses posttransplantation. Compared with the $\mathrm{NHB}_{10 \text { min }}$ group, MSCs together with restored Kupffer cells significantly decreased serum TNF $\alpha$, IFN $\gamma$, and IL2 protein secretion. Similarly, the serum protein expression of other proinflammatory cytokines, including IL17, IL1 $\beta$, and MPO, was suppressed. MSCs had no effects on Th2 cytokines such as IL4 and IL6 but clearly promoted IL10 secretion (Fig. 5a). Thus, MSC infusion suppresses Th1/Th17 immune responses but exerts no effects on Th2 responses with the exception of IL10 secretion.

\section{MSCs suppress chemokine expression and inflammatory cell infiltration in liver grafts}

Kupffer cells are known as "sensor cells" that respond to IRI and release different chemokines, which recruit large amounts of inflammatory cells that infiltrate the liver [35]. The serum protein levels of chemokines were investigated 

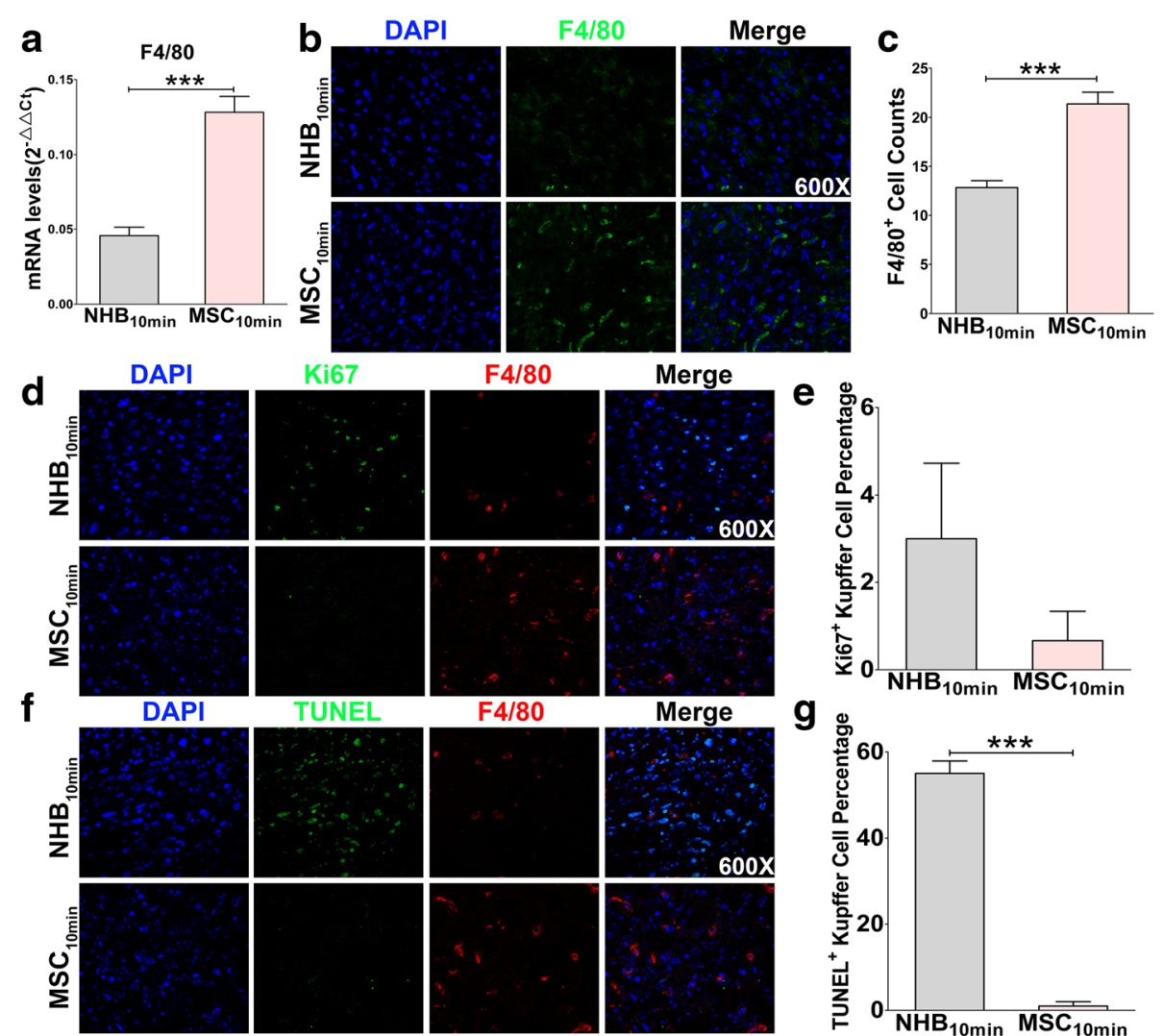

9 :

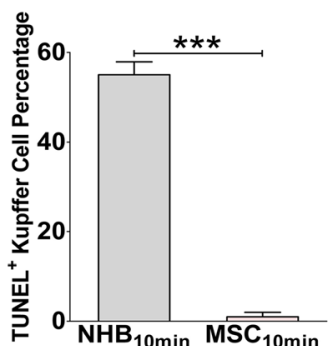

Fig. 4 Mesenchymal stem cells (MSCS) protect and restore Kupffer cells by inhibiting apoptosis but not by promoting proliferation. At $6 \mathrm{~h}$ posttransplantation, liver grafts from each group were collected for quantitative RT-PCR analysis and immunofluorescence staining. a Intrahepatic mRNA level of F4/80 was detected by quantitative RT-PCR ( $N=6$ for each group). b F4/80 immunofluorescence staining of frozen liver graft tissues were visualized by confocal scanning. Representative images from one experiment are shown at 600x magnification. c Intrahepatic F4/80positive cells in each section were counted for statistical analysis ( $N=6$ for each group). $\mathbf{d}$ Proliferation of Kupffer cells was detected by Ki67 (green) and F4/80 (red) double staining. Representative images from one experiment are shown at $600 \times$ magnification. e The percentage of Ki6 ${ }^{+}$ $\mathrm{F} 4 / 80^{+}$cells in total $\mathrm{F} 4 / 80^{+}$Kupffer cells was counted and calculated for statistical analysis ( $N=3$ for each group). $\mathbf{f}$ Apoptosis of Kupffer cells was detected by TUNEL (green) and F4/80 (red) double staining. Representative images from one experiment are shown at 600x magnification. $\mathbf{g}$ The percentage of TUNEL ${ }^{+} \mathrm{F} 4 / 80^{+}$cells in total F4/80+ Kupffer cells was counted and calculated for statistical analysis ( $N=3$ for each group). a, $\mathbf{c}, \mathbf{e}, \mathbf{g}$ Results are presented as mean \pm SEM for each group. ${ }^{* * *} P<0.001$. NHB non-heart-beating, TUNEL terminal deoxynucleotidyl transferase dUTP nick end labelling

to evaluate changes resulting from MSC infusion. Interestingly, the serum protein expression of CXCL1, CCL2, CCL4, CCL7, and CXCL10 was notably suppressed in the MSC infusion group (Fig. 5b). Intrahepatic infiltrating cells are indicative of the degree of liver inflammation; specifically, neutrophils and T cells are the most informative. Because neutrophils migrate into pathological sites and release MPO, MPO is regarded as a typical neutrophil biomarker, whereas CD3 is a classical T-cell biomarker. We performed immunohistochemical staining to detect MPO and CD3 to evaluate inflammation in liver grafts. Intrahepatic infiltration of $\mathrm{MPO}^{+}$neutrophils and $\mathrm{CD}^{+} \mathrm{T}$ cells was dramatically decreased (Fig. 5c, d and e). Our results indicated that Kupffer cell restoration, together with infused MSCs, suppresses chemokine expression and reduces neutrophil and T-cell infiltration into liver grafts post-transplantation.

\section{MSCs inhibit Kupffer cell apoptosis by secreting PGE2 in} vitro

To clarify the underlying mechanism by which MSCs inhibit Kupffer cell apoptosis, we used an in vitro cell-cell co-culture system with the murine-derived RAW264.7 cell line to represent Kupffer cells, which exclusively express F4/80 antigen on the membrane surface (Fig. 6a) [36]. Six hours after hydrogen peroxide $\left(\mathrm{H}_{2} \mathrm{O}_{2}\right)$ stimulation, Kupffer cell apoptosis was elevated in an $\mathrm{H}_{2} \mathrm{O}_{2}$ dose-dependent manner compared with that in controls, whereas co-culture with MSCs protected Kupffer cells from apoptosis in the presence of low concentrations of $\mathrm{H}_{2} \mathrm{O}_{2}(100 \mu \mathrm{M}$ and $200 \mu \mathrm{M})$. NS-398, a specific PGE2 inhibitor, dramatically reversed the reduction in apoptosis observed in the presence of MSCs (Fig. 6b and c). When stimulated with high concentrations of $\mathrm{H}_{2} \mathrm{O}_{2}$ (400 $\mu \mathrm{M}$ and $800 \mu \mathrm{M})$, MSCs lost their ability to protect 


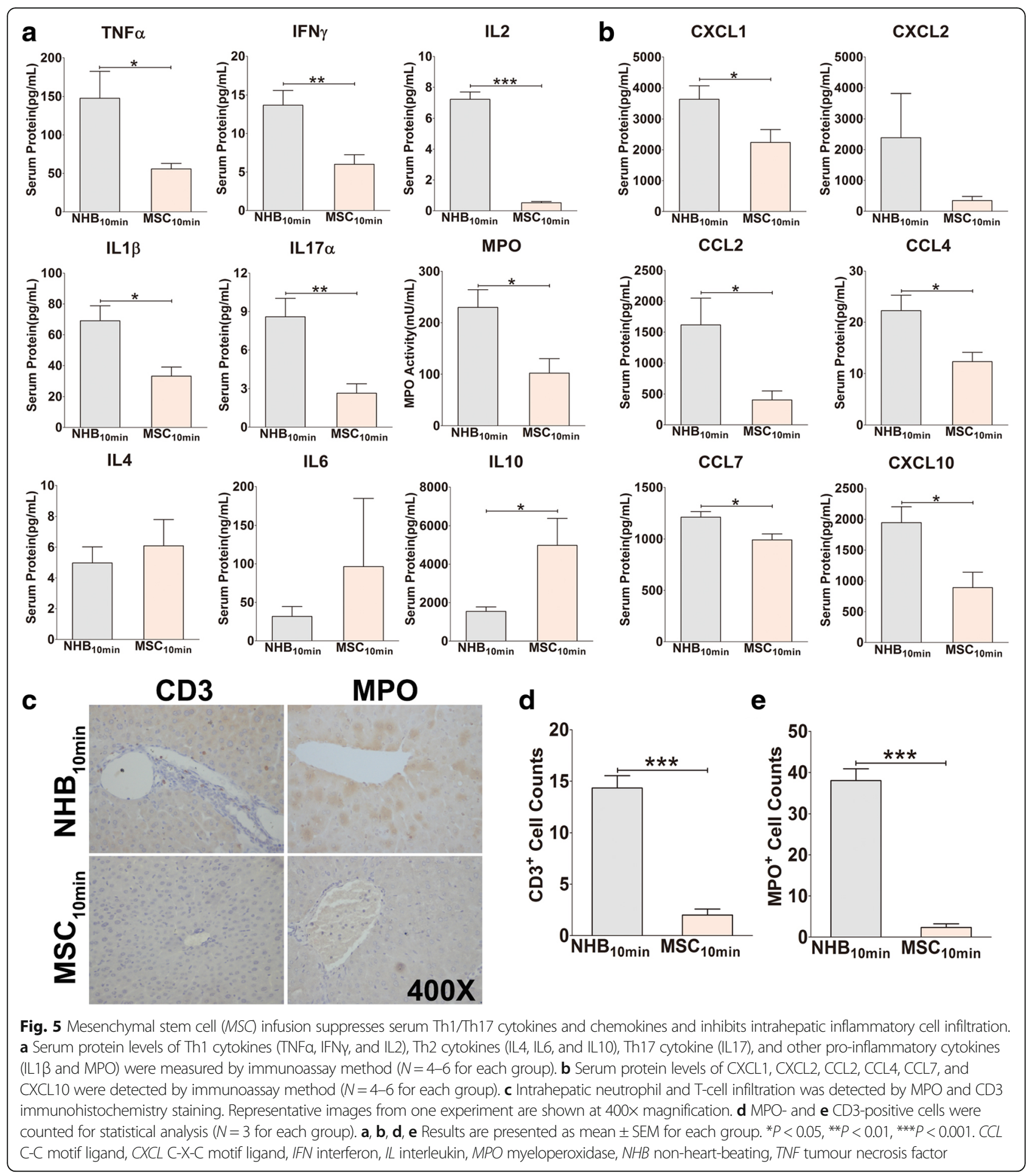

against apoptosis, regardless of PGE2 inhibition (Fig. 6c). Thus, MSC-derived PGE2 is a key factor in Kupffer cell apoptosis inhibition. Furthermore, the paracrine protective effects of MSCs on Kupffer cells were restricted, not unlimited, in our in vitro experiments.
MSC-derived PGE2 plays an essential role in inhibiting Kupffer cell apoptosis by regulating the TLR4-ERK1/2-Fas/ FasL-caspase3 signalling pathway

The accumulation of reactive oxidant species elevates TLR4 expression, activates MAPK-induced NFkB translocation, 


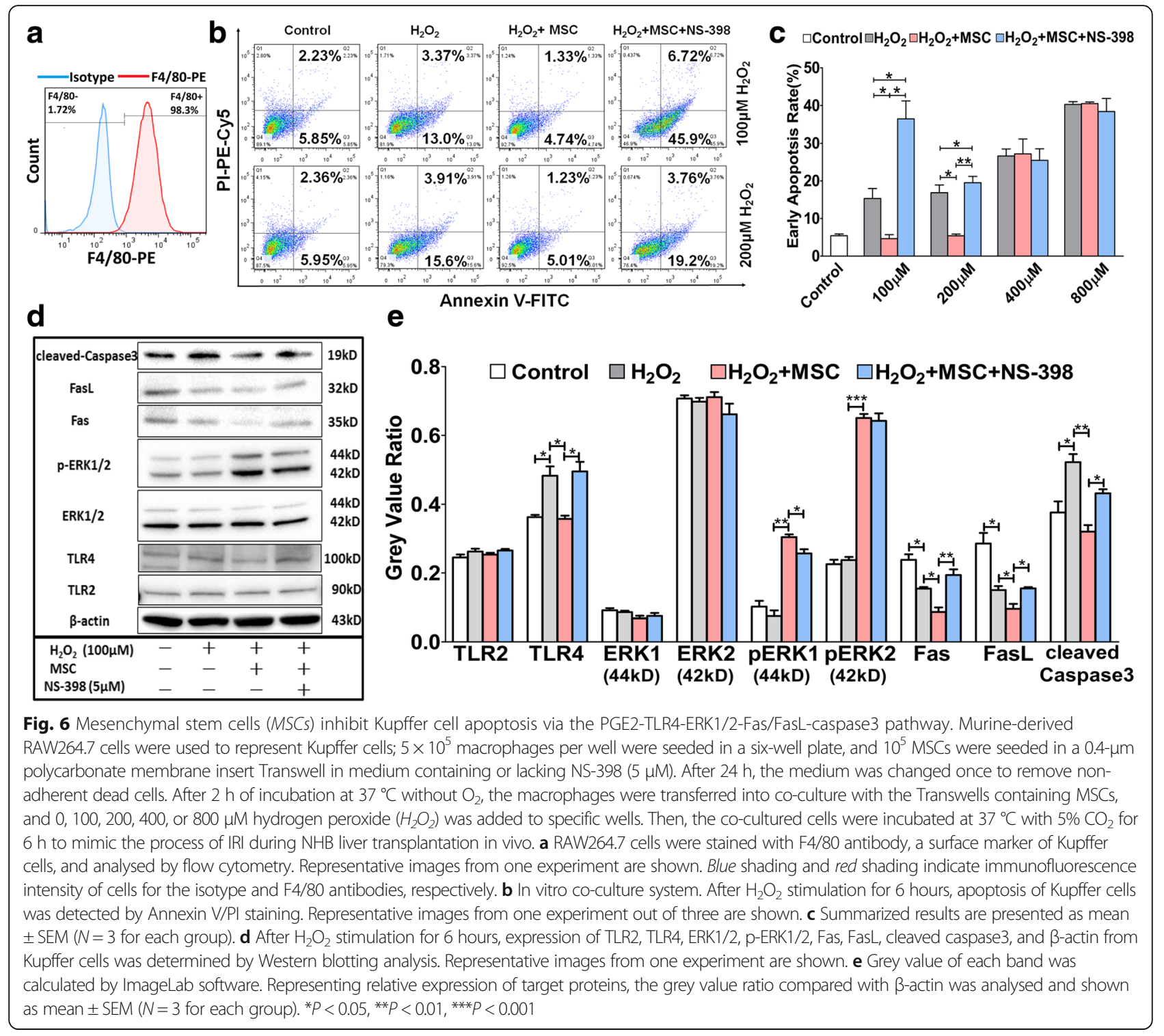

and exacerbates liver injury [37]. Peng et al. have reported the ability of elevated TLR4 to promote PKC pase3 activation of Kupffer cells [38, 39], and in other reports TLR2 and TLR4 have been found to inhibit Bcl-2 expression by reducing AKT and ERK1/2 phosphorylation [40-43]. Because we demonstrated the critical role of PGE2 in the protective effects mediated by MSCs, we performed sequential Western blotting to detect related signalling pathways. PGE2 downregulated TLR4, but not TLR2, expression in Kupffer cells, thus activating ERK1/2 phosphorylation which resulted in the reduced expression of Fas/FasL and cleaved caspase3 (Fig. 6d and e). Thus, PGE2 inhibits Kupffer cell apoptosis by regulating the TLR4-ERK1/2-Fas/FasL-caspase3 signalling pathway.

\section{Long-term safety of MSC infusion}

The long-term safety of MSC application in vivo is an inevitable question. To evaluate safety in our study, we prolonged our observation period of the MSC infusion group to 3 months. The survival rate at 3 months posttransplantation was $75 \%$, and all surviving recipients were healthy with normal serum ALT/AST levels (Fig. 7a). No tumourigenesis was detected, although two recipients died because of biliary tract obstruction, as confirmed by autopsy. Histological examination showed a relatively normal hepatocellular morphology, obvious cell infiltration, and mild hyperplasia around the portal area (Fig. 7b), which may represent a response to ischaemic biliary injury. Whether these infiltrated cells were inflammatory cells, such as neutrophils and T cells, or infused 


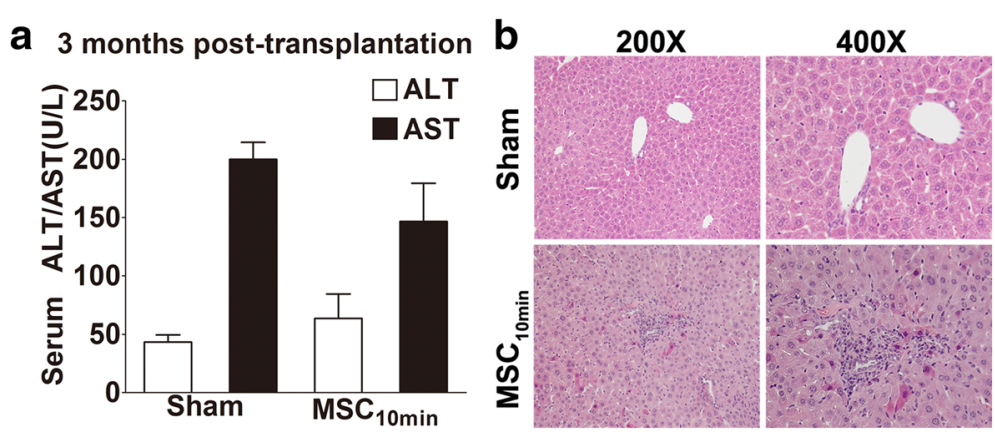

Fig. 7 Mesenchymal stem cell (MSC) infusion is safe and effective with no tumorigenesis detected during 3 months of observation. a At 3 months posttransplantation, serum alanine aminotransferase (ALT) and aspartate aminotransferase (AST) levels in the MSC $_{10 m i n}$ group showed no difference compared with the sham group. Results are presented as mean \pm SEM ( $N=6$ for each group). $\mathbf{b}$ Liver grafts were harvested for histological examination and no tumorigenesis was detected. Haematoxylin and eosin staining of grafts showed relatively normal hepatocellular morphology, cell infiltration, and mild hyperplasia around the portal area, which may represent a response to ischaemic biliary injury. Representative images are shown at 200x and 400x

MSCs requires further investigation. Our results indicate that MSC infusion is effective and safe in a mouse model of NHB liver transplantation.

\section{Discussion}

DCDs, formerly known as "non-heart-beating donors", exhibit notably different pathophysiology from that of brain death donors. DCDs can be divided into "controlled" and "uncontrolled" categories according to the Maastricht classification [44]. Although there has been considerably renewed interest in DCD donors to increase the pool of available organs, there are challenges associated with the additional hypoxic damage in DCD grafts, such as the increased incidence of primary non-function, early dysfunction, and cholangiopathy in controlled DCD transplantation [5-9]. Additionally, uncontrolled DCD grafts that experience warm ischaemic time of more than $30 \mathrm{~min}$ are excluded from transplantation worldwide, owing to the higher incidence of primary non-function, which results in a great loss of donated organs [45].

Innovative strategies and research are needed to improve the application of DCD liver grafts. However, animal studies have primarily focused on graft preservation, including ex vivo machine perfusion and modified perfusates in rat or swine models [46-50]. To our knowledge, only Liu et al. have reported syngeneic liver transplants from DCD mice; however, the surgery in their study was performed without hepatic artery reconstruction, which differs from clinical transplant procedures [51]. To strictly adhere to clinical surgery procedures, we first attempted liver transplantation from $\mathrm{C} 57 \mathrm{Bl} / 6$ to $\mathrm{C} 57 \mathrm{Bl} / 6$ mice; however, because of hepatic artery variations, the transplant surgery success rate was only approximately $30 \%$, which was not suitable for establishing an animal model. Because CBF1 mice have heterosis and do not reject liver grafts from $\mathrm{C} 57 \mathrm{Bl} / 6$ mice, we then attempted liver transplantation from $\mathrm{C} 57 \mathrm{Bl} / 6$ to $\mathrm{CBF} 1$ mice. Unexpectedly, the success rate of transplantation with hepatic artery reconstruction reached $90 \%$, and the survival rate and graft histology in this mouse model were consistent (Additional file 1: Figure S1). On the basis of a large amount of preliminary data, we established an optimal arterialized mouse NHB liver transplantation model characterized by $10 \mathrm{~min}$ of NHB time and $120 \mathrm{~min}$ of cold ischaemic time. The $\mathrm{NHB}_{5 \min }$ group showed no significant differences compared with the $\mathrm{NHB}_{0 \text { min }}$ group in terms of serum ALT/AST levels, Suzuki scores, and 14-day survival rates, thus indicating that warm ischaemia for less than 5 min did not induce obvious graft injury or damage. According to the calculation of Giraud et al. [52], $5 \mathrm{~min}$ of warm ischaemia in mice is equivalent to $42.8 \mathrm{~min}$ in humans. Thus, human DCD liver grafts with a cardiac arrest time of less than 42.8 min may be acceptable, a result consistent with the clinical criterion that DCD grafts used within 30 min of warm ischaemia are safe [45]. Furthermore, mRNA levels of pro-inflammatory cytokines associated with the Th1/Th2 response, with the exception of IL2 and IL4, decreased with increased NHB duration. The exact mechanism underlying these results remains unclear, but prolonged NHB time may potentially induce severe injury or even apoptosis of intrahepatic nonparenchymal cells, ultimately resulting in decreased mRNA levels for the majority of Th1/Th2 cytokines. However, it is unknown why IL2 and IL4 are exceptions to this trend, and further investigation is required.

MSCs have powerful immunomodulatory and regenerative capacities, thus making them a promising therapeutic option for treatment of clinical diseases. However, clinical trials investigating MSCs in liver transplantation are still in process, and the ultimate effects of MSCs on prolonged graft survival, reduced transplantation side effects, and concomitant therapy have yet to be evaluated [53].

In our study, MSC infusion dramatically ameliorated NHB-induced graft injury and increased recipient 
survival post-transplantation. Mechanistically, MSCs inhibited Kupffer cell apoptosis by producing PGE2 in an ERK1/2-dependent manner. Together, protected Kupffer cells and infused MSCs suppressed Th1/Th17 cells, which further decreased chemokine expression and inhibited inflammatory cell infiltration, thereby resulting in a reduction in NHB-induced graft injury. Furthermore, 10 min of NHB graft injury was reversed by MSC infusion. Graft injury in the MSC infusion group was not significantly different compared with grafts in the $\mathrm{NHB}_{0 \text { min }}$ group, thus suggesting promisingly clinical application of MSCs in uncontrolled DCD grafts. Uncontrolled DCD liver grafts with warm ischaemia time of less than 85.6 min may achieve outcomes comparable to those of controlled organs if combined with MSC infusion. Additionally, the lack of tumourigenesis observed during a prolonged observation time of 3 months indicates the safety and effectiveness of MSC infusion. However, additional clinical studies must be performed to verify the feasibility of our proposed method.

Kupffer cells, known as liver-resident macrophages, account for approximately $30 \%$ of liver non-parenchymal cells and more than 50\% of resident macrophages throughout the entire body [54-56] and play an important role in immunomodulation, phagocytosis, biochemical attack, and liver IRI [57]. Kupffer cells create an inflammatory milieu by generating cytotoxic ROS, cytokines such as TNF $\alpha$ and IL1 $\beta$, and neutrophil-associated chemokines such as CXCL1, CXCL2, CCL2, and CXCL10 [58-63]. In contrast, IL10 released by Kupffer cells may induce anergy in $\mathrm{T}$ cells and protect tissues against excessive injury $[64,65]$.

Interestingly, in our study, the number of F4/80-positive Kupffer cells decreased rapidly with the extension of warm ischaemia time, whereas MSC infusion restored Kupffer cells by inhibiting apoptosis. The protected Kupffer cells suppressed Th1/Th17 cells and depressed the intrahepatic infiltration of neutrophils and $\mathrm{T}$ cells by reducing cytokine and chemokine secretion, thus resulting in reduced graft injury. Moreover, the protective effects of MSCs on NHB liver grafts were dependent on the presence of Kupffer cells. Together, our data provide the first evidence of the extremely important role of Kupffer cells in determining NHB liver graft quality. In the future, Kupffer cells or F4/ 80 expression levels may be valuable in evaluating the quality of DCD liver grafts and predicting the prognosis of DCD liver transplantation.

The paracrine effects of MSCs are critical components of their immunomodulatory functions. Among numerous soluble factors, PGE2 is the most well-characterized, affecting Th17 differentiation and regulating modulatory macrophages and dendritic cells $[66,67]$. In vitro data revealed the important role of PGE2 in suppressing Kupffer cell apoptosis. We also elucidated the involvement of the
TLR4-ERK1/2-Fas/FasL-caspase3 signalling pathway in this process. Notably, the underlying mechanism revealed in our study broadens insight and allows for a better understanding of how MSCs protect NHB grafts (Additional file 2: Figure S2); however, other mechanisms involved in this protection require further investigation.

\section{Conclusions}

In conclusion, we provide the first report of an optimal arterialized mouse NHB liver transplantation model for DCD-related research and reveal the profound protective effects of MSC infusion on NHB liver grafts, which dramatically improved recipient survival post-transplantation. Moreover, we also demonstrate the critical role of PGE2 in inhibiting Kupffer cell apoptosis via the TLR4-ERK1/2caspase 3 pathway. This work presents a promising and feasible option for the clinical application of MSC infusion to protect DCD liver grafts and prolong post-transplant survival in the future.

\section{Additional files}

Additional file 1: Figure S1. C57-CBF1 transplantation showed no difference in survival and histology compared with C57-C57. (a) Photographs of NHB mice liver transplantation model. 1: Prolonged hepatic artery of graft; 2: aorta abdominalis of recipient; 3: portal vein reconstruction; 4: inferior vena cava reconstruction; 5: reconstructed hepatic artery with blood flow. (b) 14days survival rate of C57-CBF1 showed no difference compared with C57-C57 ( $N=10$ for each group, $100 \%$ vs. $90 \%, P=0.3173$ ), which had a much higher success rate in hepatic artery reconstruction ( $90 \%$ vs. $30 \%)$. (c) Histological examination of liver grafts in each group at $6 \mathrm{~h}$ post-transplantation (haematoxylin and eosin staining). (d) Suzuki score of graft injury showed no difference between two groups $(1.667 \pm 0.2108$ vs. $1.833 \pm 0.1667, N=6$ for each group, $P=0.5490)$. (DOCX $1045 \mathrm{~kb})$

Additional file 2: Figure S2. Possible mechanisms for MSCs protecting NHB liver grafts. (a) After NHB liver transplantation, warm and cold ischemia/reperfusion injury would promote the expression of TLR4 on the surface of Kupffer cells. TLR4 could inhibit activation of ERK1/2 resulting in elevated expression of Fas/FasL and cleaved-caspase3. These changes lead to apoptosis of Kupffer cells with a large amount of proinflammatory cytokine and chemokine release. These cytokines and chemokines promote the inflammatory response and inflammatory cell infiltration into liver grafts. Finally, aggravated liver graft injury reduced survival rate after NHB liver transplantation. (b) MSCs could secrete PGE2, which would inhibit the elevated expression of TLR4 on Kupffer cells after NHB liver transplantation. Then activated ERK1/2 decreased expression of Fas/FasL and cleaved-caspase3, resulting in restoration of Kupffer cells. These changes suppressed Th1/Th17 cytokine and chemokine release, and reduced neutrophil and T-cell infiltration. Finally, liver grafts of good quality guaranteed a dramatic increase in the survival rate of recipients. (DOCX $272 \mathrm{~kb})$

\section{Abbreviations}

ALT: Alanine aminotransferase; AST: Aspartate aminotransferase; CCL: C-C motif ligand; CXCL: C-X-C motif ligand; DCD: Donation after cardiac death; DMEM: Dulbecco's modified Eagle's medium; FBS: Foetal bovine serum; $\mathrm{GdCl}_{3}$ : Gadolinium chloride; $\mathrm{H}_{2} \mathrm{O}_{2}$ : Hydrogen peroxide; IDO: Indoleamine 2,3dioxygenase; IFN: Interferon; IL: Interleukin; iNOS: Inducible nitric oxide synthase; IRI: Ischaemia/reperfusion injury; IVC: Individually ventilated cages; MPO: Myeloperoxidase; MSC: Mesenchymal stem cell; NHB: Non-heart-beating; PBS: Phosphate-buffered saline; PGE2: Prostaglandin E2; RT-PCR: Real-time polymerase chain reaction; TGF: Transforming growth factor; TNF: Tumour 
necrosis factor; TUNEL: Terminal deoxynucleotidyl transferase dUTP nick end labelling

\section{Acknowledgements}

The authors thank Prof. Weimin Fan (Zhejiang University, Hangzhou, China) for the gift of immortalized T40-MSCs.

\section{Funding}

This study was supported by Innovative Research Groups of the National Natural Science Foundation of China (Grant No. 81421062) and the National Natural Science Foundation of China (Grant No. 81372626, Grant No. 81572975 , Grant No. 81400672, and Grant No. 81401320).

\section{Availability of data and materials}

The materials and data analysed during the current study are available from the corresponding author on reasonable request.

\section{Authors' contributions}

YT and JW performed the experiments and wrote the manuscript. WW contributed ideas, performed in vitro experiments, and revised the manuscript. YD analysed histological injury evaluation and drew the figures for this manuscript. ZS and HX contributed to statistical analysis and revised the manuscript. QZ and $\mathrm{WW}$ contributed with mice liver transplantation procedures and revised the manuscript. SY and SZ conceived and designed the experiments, and revised the manuscript. All authors read and approved the final manuscript.

\section{Competing interests}

The authors declare that they have no competing interests.

\section{Ethics approval and consent to participate}

Animal feeding practices and all experiments involving animals were conducted in accordance with the Guidelines for the Care and Use of Laboratory Animals and received the approval of the Animal Ethics Committees of Zhejiang University (Hangzhou, China).

\section{Author details}

'Division of Hepatobiliary and Pancreatic Surgery, Department of Surgery, the First Affiliated Hospital, School of Medicine, Zhejiang University, Hangzhou, China. ${ }^{2}$ Key Laboratory of Combined Multi-organ Transplantation, Ministry of Public Health, Key Laboratory of Organ Transplantation, Hangzhou, Zhejiang Province, China. ${ }^{3}$ Collaborative Innovation Center for Diagnosis Treatment of Infectious Diseases, Hangzhou, Zhejiang Province, China.

Received: 8 August 2016 Revised: 20 September 2016 Accepted: 1 October 2016 Published online: 27 October 2016

\section{References}

1. Starzl TE, Marchioro TL, Vonkaulla KN, Hermann G, Brittain RS, Waddell WR. Homotransplantation of the liver in humans. Surg Gynecol Obstet. 1963;117: 659-76.

2. Sass DA, Reich DJ. Liver transplantation in the 21st century: expanding the donor options. Gastroenterol Clin North Am. 2011;40:641-58.

3. Xu J, Sayed BA, Casas-Ferreira AM, Srinivasan P, Heaton N, Rela M, et al. The impact of ischemia/reperfusion injury on liver allografts from deceased after cardiac death versus deceased after brain death donors. PLoS One. 2016;11, e0148815.

4. Tuttle-Newhall JE, Krishnan SM, Levy MF, McBride V, Orlowski JP, Sung RS. Organ donation and utilization in the United States: 1998-2007. Am J Transplant. 2009;9:879-93.

5. Garcia-Valdecasas JC, Tabet J, Valero R, Deulofeu R, Taura P, Rull R, et al. Evaluation of ischemic injury during liver procurement from non-heartbeating donors. Eur Surg Res. 1999;31:447-56.

6. Valero R, Garcia-Valdecasas JC, Net M, Beltran J, Ordi J, Gonzalez FX, et al. Larginine reduces liver and biliary tract damage after liver transplantation from non-heart-beating donor pigs. Transplantation. 2000;70:730-7.

7. Schon MR, Kollmar O, Wolf S, Schrem H, Matthes M, Akkoc N, et al. Liver transplantation after organ preservation with normothermic extracorporeal perfusion. Ann Surg. 2001;233:114-23.

8. St Peter SD, Imber CJ, Lopez I, Hughes D, Friend PJ. Extended preservation of non-heart-beating donor livers with normothermic machine perfusion. $\mathrm{Br}$ J Surg. 2002:89:609-16.
9. Schon MR, Hunt CJ, Pegg DE, Wight DG. The possibility of resuscitating livers after warm ischemic injury. Transplantation. 1993;56:24-31.

10. Liu WH, Song FQ, Ren LN, Guo WQ, Wang T, Feng YX, et al. The multiple functional roles of mesenchymal stem cells in participating in treating liver diseases. J Cell Mol Med. 2015;19:511-20.

11. Horwitz EM, Le Blanc K, Dominici M, Mueller I, Slaper-Cortenbach I, Marini FC, et al. Clarification of the nomenclature for MSC: The International Society for Cellular Therapy position statement. Cytotherapy. 2005;7:393-5.

12. Uccelli A, Moretta L, Pistoia V. Mesenchymal stem cells in health and disease. Nat Rev Immunol. 2008:8:726-36.

13. English K, Wood KJ. Mesenchymal stromal cells in transplantation rejection and tolerance. Cold Spring Harb Perspect Med. 2013;3:a015560.

14. Shi Y, Hu G, Su J, Li W, Chen Q, Shou P, et al. Mesenchymal stem cells: a new strategy for immunosuppression and tissue repair. Cell Res. 2010;20:510-8.

15. Pileggi A. Mesenchymal stem cells for the treatment of diabetes. Diabetes 2012;61:1355-6.

16. Papadopoulou A, Yiangou M, Athanasiou E, Zogas N, Kaloyannidis P, Batsis I, et al. Mesenchymal stem cells are conditionally therapeutic in preclinical models of rheumatoid arthritis. Ann Rheum Dis. 2012;71:1733-40.

17. Aquino JB, Bolontrade MF, Garcia MG, Podhajcer OL, Mazzolini G. Mesenchymal stem cells as therapeutic tools and gene carriers in liver fibrosis and hepatocellular carcinoma. Gene Ther. 2010;17:692-708.

18. Li J, Zhang L, Xin J, Jiang L, Li J, Zhang T, et al. Immediate intraportal transplantation of human bone marrow mesenchymal stem cells prevents death from fulminant hepatic failure in pigs. Hepatology. 2012;56:1044-52.

19. Yokota S, Yoshida O, Ono Y, Geller DA, Thomson AW. Liver transplantation in the mouse: insights into liver immunobiology, tissue injury, and allograft tolerance. Liver Transpl. 2016;22:536-46.

20. Yan S, Ding Y, Tian Y, Lu Z, Wang Y, Zhang Q, et al. MHC-mismatched mice liver transplantation promotes tumor growth in liver graft. Cancer Lett. 2014;351:162-71.

21. Ye Y, Yan S, Jiang G, Zhou L, Xie H, Xie X, et al. Galectin-1 prolongs survival of mouse liver allografts from Flt3L-pretreated donors. Am J Transplant. 2013;13:569-79

22. Pan N, Liu Z, He J, Li S, Lv X, Wang L, et al. Comparison of methods for the reconstruction of the hepatic artery in mouse orthotopic liver transplantation. PLoS One. 2015:10, e0133030.

23. Wang $Y$, Tian $Y$, Ding $Y$, Wang J, Yan S, Zhou L, et al. MiR-152 may silence translation of CaMK II and induce spontaneous immune tolerance in mouse liver transplantation. PLoS One. 2014;9, e105096.

24. Ji H, Liu Y, Zhang Y, Shen XD, Gao F, Busuttil RW, et al. T-cell immunoglobulin and mucin domain 4 (TIM-4) signaling in innate immunemediated liver ischemia-reperfusion injury. Hepatology. 2014;60:2052-64.

25. Liu Y, Ji H, Zhang Y, Shen X, Gao F, He X, et al. Recipient T cell TIM-3 and hepatocyte galectin-9 signalling protects mouse liver transplants against ischemia-reperfusion injury. J Hepatol. 2015;62:563-72.

26. Liu Y, Ji H, Zhang Y, Shen XD, Gao F, Nguyen TT, et al. Negative CD4 + TIM3 signaling confers resistance against cold preservation damage in mouse liver transplantation. Am J Transplant. 2015;15:954-64.

27. Pellicoro A, Ramachandran P, Iredale JP, Fallowfield JA. Liver fibrosis and repair: immune regulation of wound healing in a solid organ. Nat Rev Immunol. 2014;14:181-94.

28. Wang ZY, Burlak C, Klaunig JE, Kamendulis LM. Development of a cytokineproducing immortalized murine Kupffer cell line. Cytokine. 2014:70:165-72.

29. Farrell E, Wielopolski $P$, Pavljasevic $P$, van Tiel S, Jahr H, Verhaar J, et al. Effects of iron oxide incorporation for long term cell tracking on MSC differentiation in vitro and in vivo. Biochem Biophys Res Commun. 2008;369:1076-81.

30. Xu N, Liu H, Qu F, Fan J, Mao K, Yin Y, et al. Hypoxia inhibits the differentiation of mesenchymal stem cells into osteoblasts by activation of Notch signaling. Exp Mol Pathol. 2013;94:33-9.

31. Gholamrezanezhad A, Mirpour S, Bagheri M, Mohamadnejad M, Alimoghaddam $K$, Abdolahzadeh $L$, et al. In vivo tracking of 111 In-oxine labeled mesenchymal stem cells following infusion in patients with advanced cirrhosis. Nucl Med Biol. 2011;38:961-7.

32. Gao J, Dennis JE, Muzic RF, Lundberg M, Caplan Al. The dynamic in vivo distribution of bone marrow-derived mesenchymal stem cells after infusion. Cells Tissues Organs. 2001;169:12-20.

33. Liska V, Slowik P, Eggenhofer E, Treska V, Renner P, Popp FC, et al. Intraportal injection of porcine multipotent mesenchymal stromal cells augments liver regeneration after portal vein embolization. In Vivo. 2009;23:229-35.

34. Ding $H$, Peng $R$, Reed $E_{\text {, }} \mathrm{i}$ QQ. Effects of Kupffer cell inhibition on liver function and hepatocellular activity in mice. Int J Mol Med. 2003;12:549-57. 
35. van Golen RF, van Gulik TM, Heger M. The sterile immune response during hepatic ischemia/reperfusion. Cytokine Growth Factor Rev. 2012;23:69-84.

36. Zhao M, Chen J, Zhu P, Fujino M, Takahara T, Toyama S, et al. Dihydroquercetin (DHQ) ameliorated concanavalin A-induced mouse experimental fulminant hepatitis and enhanced HO-1 expression through MAPK/Nrf2 antioxidant pathway in RAW cells. Int Immunopharmacol. 2015;28:938-44.

37. Meng Z, Yan C, Deng Q, Gao DF, Niu XL. Curcumin inhibits LPS-induced inflammation in rat vascular smooth muscle cells in vitro via ROS-relative TLR4-MAPK/NF-kappaB pathways. Acta Pharmacol Sin. 2013;34:901-11.

38. Peng Y, Sigua CA, Murr MM. Protein kinase C-zeta mediates apoptosis of mouse Kupffer cells via ERK-1/2: a novel mechanism. Surgery. 2011;149:135-42.

39. Peng Y, Sigua CA, Rideout D, Murr MM. Deletion of toll-like receptor-4 downregulates protein kinase C-zeta and attenuates liver injury in experimental pancreatitis. Surgery. 2008;143:679-85.

40. Tichomirowa MA, Theodoropoulou M, Daly AF, Yassouridis A, Hansen S, Lu $J$, et al. Toll-like receptor-4 is expressed in meningiomas and mediates the antiproliferative action of paclitaxel. Int J Cancer. 2008;123:1956-63.

41. Sanchez D, Rojas M, Hernandez I, Radzioch D, Garcia LF, Barrera LF. Role of TLR2- and TLR4-mediated signaling in Mycobacterium tuberculosis-induced macrophage death. Cell Immunol. 2010;260:128-36.

42. Lv Y, Qian Y, Ou-Yang A, Fu L. Hydroxysafflor Yellow A attenuates neuron damage by suppressing the lipopolysaccharide-induced TLR4 pathway in activated microglial cells. Cell Mol Neurobiol. 2016;36(8):1241-56.

43. Kim DE, Kim B, Shin HS, Kwon HJ, Park ES. The protective effect of hispidin against hydrogen peroxide-induced apoptosis in $\mathrm{H} 9 \mathrm{c} 2$ cardiomyoblast cells through Akt/ GSK-3beta and ERK1/2 signaling pathway. Exp Cell Res. 2014;327:264-75.

44. Mason DP, Murthy SC, Gonzalez-Stawinski GV, Budev MM, Mehta AC, McNeill AM, et al. Early experience with lung transplantation using donors after cardiac death. J Heart Lung Transplant. 2008;27:561-3.

45. Mateo R, Cho Y, Singh G, Stapfer M, Donovan J, Kahn J, et al. Risk factors for graft survival after liver transplantation from donation after cardiac death donors: an analysis of OPTN/UNOS data. Am J Transplant. 2006;6:791-6.

46. Guarrera JV, Henry SD, Samstein B, Odeh-Ramadan R, Kinkhabwala M, Goldstein MJ, et al. Hypothermic machine preservation in human liver transplantation: the first clinical series. Am J Transplant. 2010;10:372-81.

47. Cobert ML, West LM, Jessen ME. Machine perfusion for cardiac allograft preservation. Curr Opin Organ Transplant. 2008;13:526-30.

48. de Rougemont O, Breitenstein S, Leskosek B, Weber A, Graf R, Clavien PA, et al. One hour hypothermic oxygenated perfusion (HOPE) protects nonviable liver allografts donated after cardiac death. Ann Surg. 2009;250:674-83.

49. Imber CJ, St Peter SD, Lopez de Cenarruzabeitia I, Pigott D, James T, Taylor $R$, et al. Advantages of normothermic perfusion over cold storage in liver preservation. Transplantation. 2002;73:701-9.

50. Hong JC, Koroleff D, Xia V, Chang CM, Duarte SM, Xu J, et al. Regulated hepatic reperfusion mitigates ischemia-reperfusion injury and improves survival after prolonged liver warm ischemia: a pilot study on a novel concept of organ resuscitation in a large animal model. J Am Coll Surg. 2012;214:505-15.

51. Liu Q, Rehman H, Krishnasamy Y, Schnellmann RG, Lemasters JJ, Zhong Z. Improvement of liver injury and survival by JNK2 and iNOS deficiency in liver transplants from cardiac death mice. J Hepatol. 2015;63:68-74.

52. Giraud S, Hauet T, Eugene M, Mauco G, Barrou B. A new preservation solution (SCOT 15) improves the islet isolation process from pancreata of non-heart-beating donors: a Murine model. Transplant Proc. 2009:41:3293-5.

53. Obermajer N, Popp FC, Johnson CL, Benseler V, Dahlke MH. Rationale and prospects of mesenchymal stem cell therapy for liver transplantation. Curr Opin Organ Transplant. 2014;19:60-4.

54. Naito M, Hasegawa G, Ebe Y, Yamamoto T. Differentiation and function of Kupffer cells. Med Electron Microsc. 2004;37:16-28.

55. Wisse E. Observations on the fine structure and peroxidase cytochemistry of normal rat liver Kupffer cells. J Ultrastruct Res. 1974;46:393-426.

56. Wisse E. Kupffer cell reactions in rat liver under various conditions as observed in the electron microscope. J Ultrastruct Res. 1974;46:499-520.

57. Decker K. Biologically active products of stimulated liver macrophages (Kupffer cells). Eur J Biochem. 1990;192:245-61.

58. Mosser DM, Edwards JP. Exploring the full spectrum of macrophage activation. Nat Rev Immunol. 2008:8:958-69.

59. Zhai Y, Shen XD, Gao F, Zhao A, Freitas MC, Lassman C, et al. CXCL10 regulates liver innate immune response against ischemia and reperfusion injury. Hepatology. 2008;47:207-14.
60. Toshchakov V, Jones BW, Perera PY, Thomas K, Cody MJ, Zhang S, et al. TLR4, but not TLR2, mediates IFN-beta-induced STAT1alpha/beta-dependent gene expression in macrophages. Nat Immunol. 2002;3:392-8.

61. Eash KJ, Greenbaum AM, Gopalan PK, Link DC. CXCR2 and CXCR4 antagonistically regulate neutrophil trafficking from murine bone marrow. J Clin Invest. 2010;120:2423-31.

62. Uchida Y, Freitas MC, Zhao D, Busuttil RW, Kupiec-Weglinski JW. The inhibition of neutrophil elastase ameliorates mouse liver damage due to ischemia and reperfusion. Liver Transpl. 2009;15:939-47.

63. Lentsch AB, Yoshidome H, Cheadle WG, Miller FN, Edwards MJ. Chemokine involvement in hepatic ischemia/reperfusion injury in mice: roles for macrophage inflammatory protein-2 and Kupffer cells. Hepatology. 1998;27:507-12.

64. Frangogiannis NG, Mendoza LH, Lindsey ML, Ballantyne CM, Michael LH, Smith CW, et al. IL-10 is induced in the reperfused myocardium and may modulate the reaction to injury. J Immunol. 2000;165:2798-808.

65. Zingarelli B, Yang Z, Hake PW, Denenberg A, Wong HR. Absence of endogenous interleukin 10 enhances early stress response during postischaemic injury in mice intestine. Gut. 2001;48:610-22.

66. Duffy MM, Pindjakova J, Hanley SA, McCarthy C, Weidhofer GA, Sweeney EM, et al. Mesenchymal stem cell inhibition of T-helper 17 celldifferentiation is triggered by cell-cell contact and mediated by prostaglandin E2 via the EP4 receptor. Eur J Immunol. 2011;41:2840-51.

67. Zhang Y, Cai W, Huang Q, Gu Y, Shi Y, Huang J, et al. Mesenchymal stem cells alleviate bacteria-induced liver injury in mice by inducing regulatory dendritic cells. Hepatology. 2014;59:671-82.

\section{Submit your next manuscript to BioMed Central and we will help you at every step:}

- We accept pre-submission inquiries

- Our selector tool helps you to find the most relevant journal

- We provide round the clock customer support

- Convenient online submission

- Thorough peer review

- Inclusion in PubMed and all major indexing services

- Maximum visibility for your research

Submit your manuscript at www.biomedcentral.com/submit
Biomed Central 